\title{
PREFACE
}

\section{Changes in climatic extremes over mainland China}

\author{
G. $\operatorname{Ren}^{1, *}$, Z. Guan ${ }^{2}$, X. Shao ${ }^{3}$, D. Y. Gong ${ }^{4}$ \\ ${ }^{1}$ Laboratory for Climate Studies, National Climate Centre, China Meteorological Administration, Beijing 100081, PR China \\ ${ }^{2}$ Key Laboratory of Meteorological Disaster of the Ministry of Education, Nanjing University of Information Science and \\ Technology, Nanjing 210044, PR China \\ ${ }^{3}$ Institute of Geographical Sciences and Natural Resources Research, Chinese Academy of Sciences, Beijing 100101, PR China \\ ${ }^{4}$ State Key Laboratory of Earth Surface Processes and Resource Ecology, Beijing Normal University, Beijing 100087, PR China
}

\begin{abstract}
This Climate Research Special includes 10 studies reporting recent findings on change in climatic extremes in mainland China, including its characteristics, possible causes and impacts. This preface provides a summary of research results and their implications for detecting, projecting and adapting to regional climate change.
\end{abstract}

KEY WORDS: Climate change - Observation - Climate model - Temperature - Precipitation · Paleo-record $\cdot$ Circulation anomalies $\cdot$ Hazard risk

\section{INTRODUCTION}

To investigate whether or not, or to what extent, extreme climatic events have increased in frequency due to climate warming (IPCC 2007) requires datasets with at least daily resolution, which are unavailable for many regions of the world (Easterling et al. 1997, Alexander et al. 2009). In spite of this, studies on extreme climatic change have been conducted by applying daily climatic data with high quality and dense observational sites (e.g. Peterson et al. 2008, Choi et al. 2009, Trewin \& Vermont 2010). When the study regions are large enough in spatial scale (e.g. encompassing mainland China), the results from such studies can be useful for understanding the causes and impacts of global and regional climate change.

A series of national research projects has been launched for regional climate change detection and projection in mainland China. A few of the projects also support studies on extreme climatic events (e.g. Qian et al. 2007, Ding \& Ren 2008, Ren et al. 2010). One of the projects, on past change and impacts of major extreme climatic events over mainland China in the past century (Project No. 2007BAC29B02), is supported by the Ministry of Sciences and Technology of China (MOST) for the period 2007-2011. Changes in frequency and intensity of major extreme climatic events have occurred for at least the past 60 years in China (Ren et al. 2010). Decadal and multi-decadal variability of intense rainfall and drought events have been found for periods of the past 2000 years by applying proxy data (Huang et al. 2010, Hao et al. 2010), providing an historical perspective for current changes.

This CR Special contains 10 studies, mostly supported by MOST. The authors present the latest research on observed trends in extreme temperature, precipitation, drought, tropical cyclones, strong wind and dust storms over mainland China, climate reconstruction based on tree-ring data and historical documents of drought events and ice/snow storm events in the past in different regions of mainland China, decadal and multi decadal variability of intense precipitation events and their linkage to circulation anomalies, performance of the BCC_CSM model in simulating 
extreme precipitation over eastern China, and the assessment of drought risk to agriculture. Although these studies alone cannot answer the question on whether or not the frequency of extreme climatic events at global and continental scales have increased as the climate has warmed, they do provide a substantial input to our knowledge of extreme climatic change in a region with one-fifth of the world's population and where vulnerability of social and economic systems to climatic change and variability is exceptionally high.

\section{CURRENT TRENDS}

Previous studies indicated a coherent warming trend across mainland China during the past $50 \mathrm{yr}$, based on mean surface air temperature and extreme temperature events, but less consistent trends were found with regard to annual and seasonal precipita- tion; almost all analyses showed a general decline in the frequency of land-falling tropical cyclones and dust storms (e.g. Zhai \& Pan 2003, 2005, Ren et al. 2005, 2010, Ding \& Ren 2008). In this Special, 2 studies report on recent progress in analyzing the observed trends in major extreme climatic events.

Ren et al. (2011, this Special) present their latest analysis of an integrated index and its temporal change for the period 1956-2009. The index, termed the Integrated Extreme Climate Index (IECI), is composed of 7 indicators representing the most frequently observed extreme events in mainland China: country-average frequencies of (1) high temperature, (2) low temperature, (3) intense precipitation, (4) dust storms, (5) strong wind events, (6) meteorological droughts, and (7) land-falling tropical cyclones (TCs) (Fig. 1). The authors assign varied weights to the individual indicators, based on economic losses and casualties induced by the events, and then use the

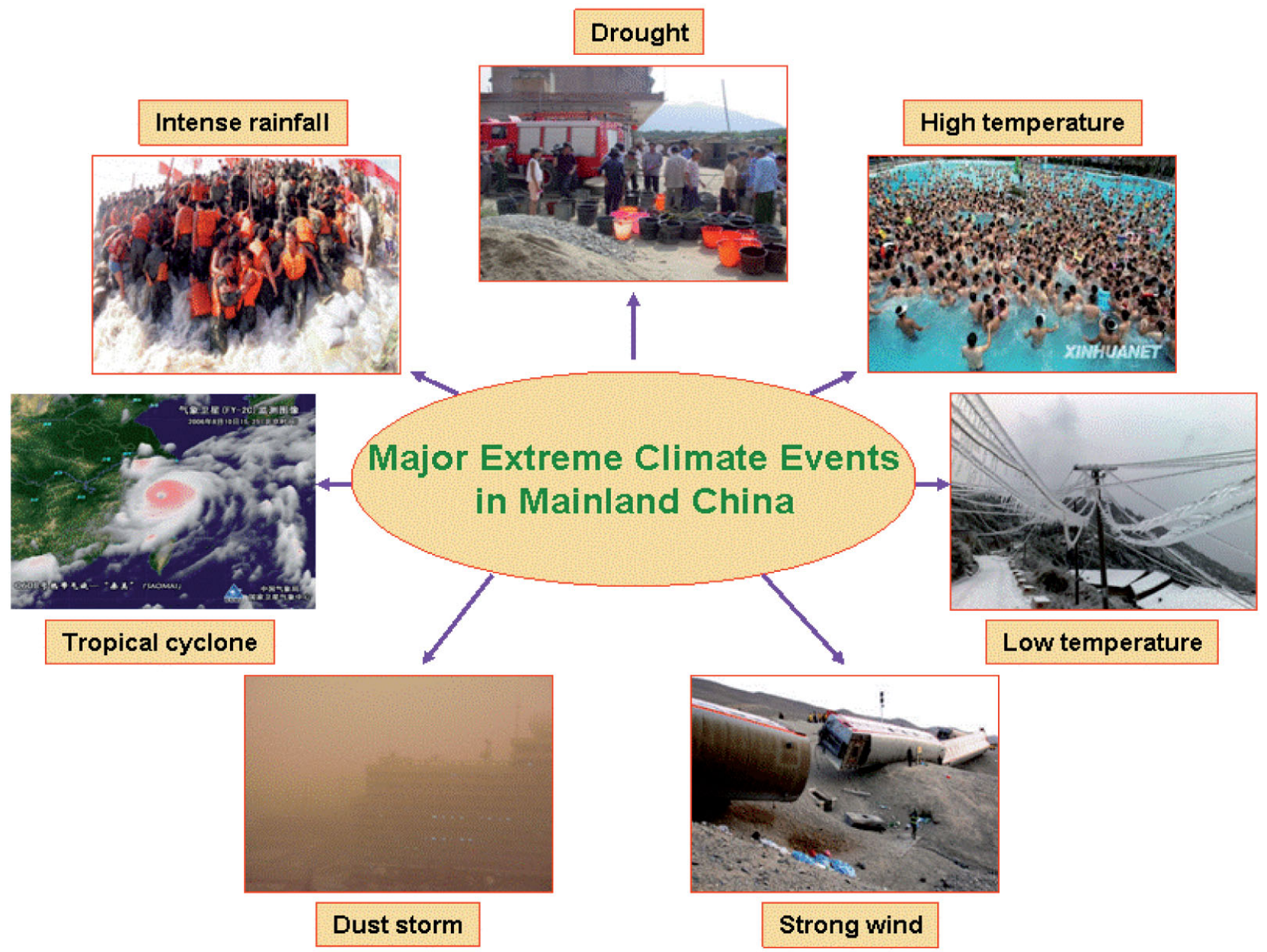

Fig. 1. Major extreme weather and climate events in mainland China. Photos: National Climate Center (NCC), National Satellite Meteorological Center (NSMC) of China Meteorological Administration (CMA), Xinhua News, Xinhuanet 
weighted sum of the standardized values of the indicators to form the IECI.

Although the individual indicators experience more or less significant change, the IECI undergoes no significant increase or decrease during the same time period, though there is clear decadal variation. The trends of the individual indicators are consistent with the previous findings, including significant increases in drought area and in the frequency of high temperature events, along with a non-significant increase in the frequency of intense precipitation events; in addition, a significant decline in frequencies of low-temperature and strong-wind events and dust storms, along with a non-significant decline in the number of land-falling TCs (Fig. 2). Ren et al. (2011) conclude that the frequency of the most damaging extreme climatic events in mainland China did not increase in 1956-2009.

Zhou \& Ren (2011, this Special) use homogeneityadjusted daily temperature data of all national stations to analyze the spatial and temporal change of extreme temperature events for 1961-2008. The analysis shows a significant reduction in frost and ice days, cool nights and cold days, an increasing frequency of summer days and tropical nights, especially in the middle and lower reaches of the Yangtze River and in southern Southwest China, and an increasing number of warm nights and warm days. The analysis in Zhou \& Ren (2011), in combination with previous studies, shows that the urbanization effect on extreme temperature indices is very significantat least in North China-for the downward trend in number of frost days, diurnal temperature range (DTR), cool nights and cool days, and also for the upward trend of summer days, tropical nights, highest and lowest minimum temperature, and warm nights.

\section{HISTORICAL CHANGE}

Few studies have been conducted to investigate change in extreme climatic events in mainland China over the past centuries (Ding \& Ren 2008). This CR Special includes 2 studies on historical change in

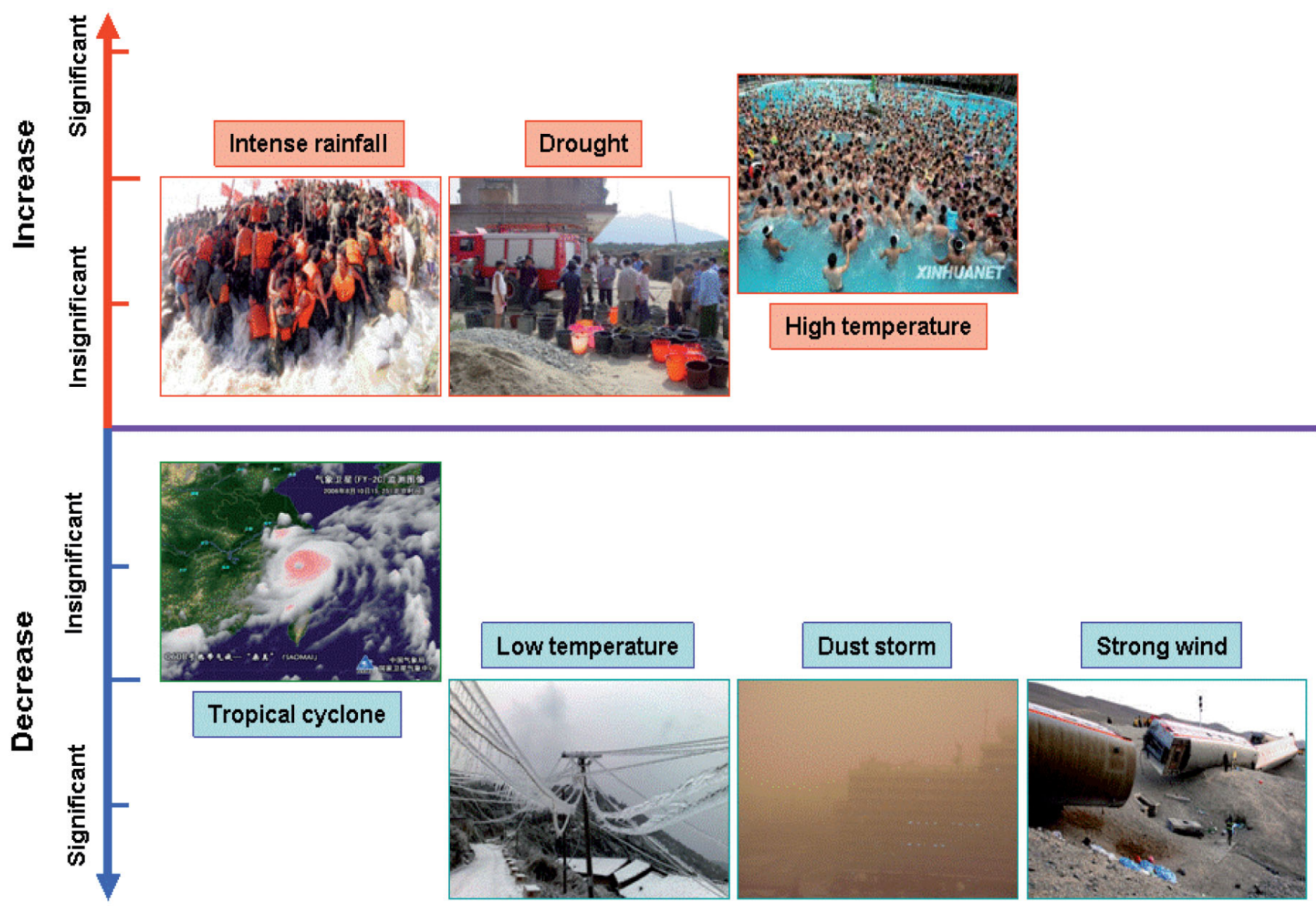

Fig. 2. Trends in frequency of major extreme climate events in mainland China from the mid-1950s to 2010. Photos: see Fig. 1 
frequency and duration of extreme climate events based on tree-ring data and documental records. The reconstructions of historical extremes provide a framework for assessing recent change in droughts and ice/snow storm events.

Y. Zhang et al. (2011, this Special) apply a regional tree-ring data network consisting of 12 tree-ring chronological series to analyze severe and persistent drought events during 1700-2005 in the Qilian Mountains, NE Tibetan Plateau. (1) They identify 98 drought years, including 15 severe and 5 extreme drought years during the past 306 years, and the drought events usually reccurred in succession or 1 to 2 years after the previous ones. (2) They show that drought events in the 20th century were more frequent than in the 18th and 19th centuries, and the multi-year drought event in the 1920s and 1930s had the longest duration during the study period. (3) They also find that this severe drought event began in the western Qilian Mountains and propagated toward the central and eastern parts of the study area, with the most severe dry spell occurring in the easternmost part of the mountains in 1928. The severe drought of 1927-1930 in Gansu and Shanaxi Provinces east of the Qilian Mountains is well documented, and may have claimed millions of lives (Zeng et al. 2009).

Hao et al. (2011, this Special) use documental records of the past $500 \mathrm{yr}$ to analyze the similarities and differences of the early 2008 ice/snow storm event with those documented historically. The early 2008 storm event occurred in more than 20 provinces in central and southern China, and it caused serious economic losses. The records are from varied historical books and personal notes, and from the Yu-XueFen-Cun archives (historical records of rain and snow in soils), which recorded dates, durations and infiltrating depths of rainfall and snowfall in soils for individual precipitation events in 18 provinces during 1736-1911 (Fig. 3). The authors identify 3 historical cases in 1578, 1620, and 1796-1797, which are very similar in severity and duration to the event in early 2008. With respect to the long-term temperature series (Hao et al. 2011, their Fig. 5), the historical ice/snow storm events tended to occur at the end of multi-decadal warm periods, probably signaling a climate shift to a colder regime. This is an interesting phenomenon which needs to be further investigated.

\section{LINKAGE OF EXTREMES WITH CIRCULATION ANOMALIES}

Although marked trends in the frequency of some extreme climate events have been associated with anthropogenic increase in atmospheric $\mathrm{CO}_{2}$ concentration at a global scale (Stott et al. 2010, Christidis et al. 2011), it is difficult to find such a relationship at regional scales, especially for precipitation extremes. It is possible, however, to relate the observed change and variability in extremes with anomalies of atmospheric or oceanic circulation, and with sources of moisture, as shown by 4 studies in this Special.

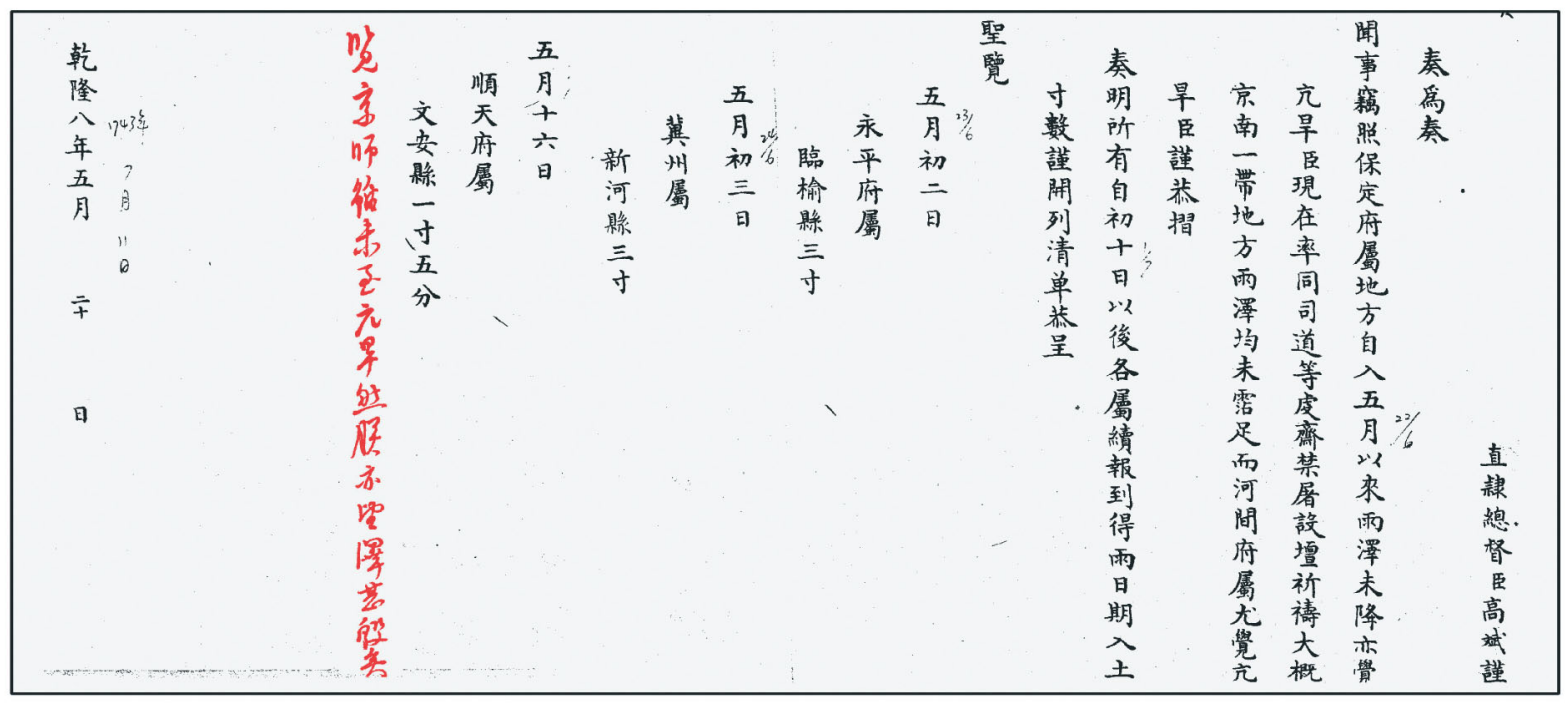

Fig. 3. Case page of the Yu-Xue-Fen-Cun reports (soil infiltration records of rain and snow) for 11 July 1743 regarding a severe drought lasting from 22 June to 11 July 1743 in Baoding Province, south of Beijing, and records of rainfall in 3 counties of other provinces. The red characters are the instruction from Emperor Qianlong (Forbidden City archives, Beijing; courtesy of Z.X. Zhao) 
Guan et al. (2011, this Special) analyze circulation anomalies in regional mean daily precipitation extreme events over the middle and lower reaches of the Yangtze River in summer, using NCEP/NCAR reanalysis data and daily precipitation data from 743 stations in China. They identify 93 extreme precipitation events for 1979-2008, but these extreme events occur with different frequencies from one decade to another. They identify 2 types of anomalous circulation patterns related to the extreme events: one is characterized by an anomalous cyclone over the study area and an anomalous anticyclone in the South China Sea and tropical NW Pacific in the lower and middle troposphere, and the other by a deep anomalous cyclone tilting westward from the low layers to the upper troposphere with an anomalous anticyclonic circulation at the lower and middle troposphere over the South China Sea and regions northeast of the study area. The 2 anomalous circulation patterns are related to different thermal forcings and water vapor transfer into the study area, but all lead to the marked increase in frequency of extreme precipitation events in the middle and lower reaches of the Yangtze River in summer.

Mao et al. (2011, this Special) analyze the relationship between the Arctic Oscillation (AO) and extreme precipitation events (daily precipitation greater than the 80th or 90th percentile) during boreal winters from 1954-2009. The AO has a significant positive correlation with the frequency of extreme precipitation events during January and

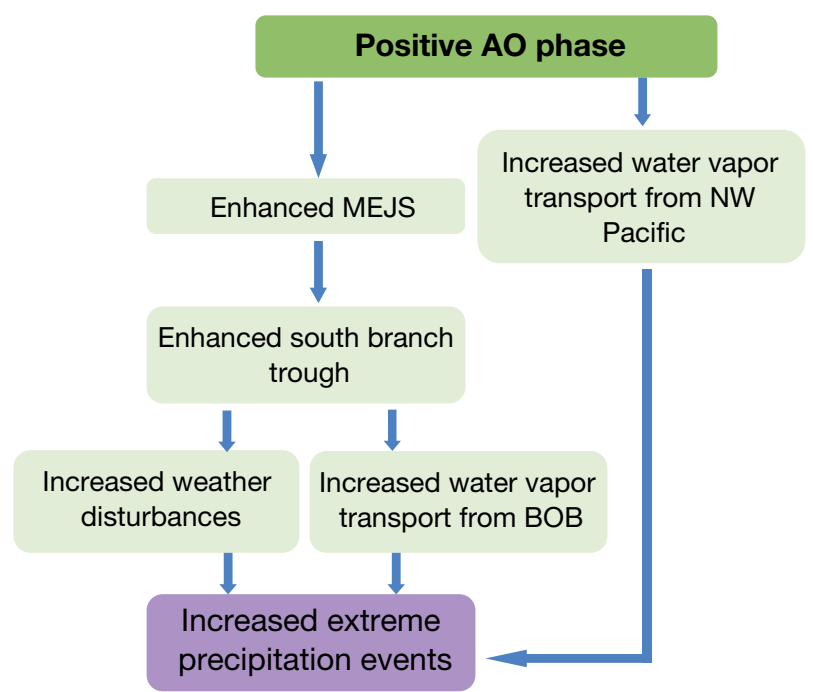

Fig. 4. Association between the positive phase of the Arctic Oscillation (AO) and the increased frequency of intense precipitation events in central and southern China (provided by R. Mao). MEJS: Central East jet stream; BOB: Bay of Bengal
February. Of all 287 stations analyzed, 83\% have positive correlation coefficients and $35 \%$ of these (mainly in central-southern China) are significant at the 0.05 confidence level. A positive AO phase is accompanied by a stronger-than-normal Central East jet stream (MEJS) and a deepened Southern Branch Trough (SBT) over the Bay of the Bengal. The deepened SBT enhances synoptic scale disturbance in vertical motion and water vapor transport in the low to middle troposphere over central-southern China, leading to more extreme precipitation events in January and February (Fig. 4).

Wang et al. (2011, this Special) investigate the variation in heavy rainfall during June-July over the Jiang-Huai Basin and its linkage with circulation anomalies. They use an empirical orthogonal function (EOF) analysis, and show 2 significant modes besides the dominant basin-wide in-phase mode: (1) a north-south dipole (out-of-phase) pattern; (2) an east-west dipole pattern. The patterns are often associated with floods and drought in the study region. During the 'south flood and north drought' (SF/ND) phase of the 2nd EOF mode, both the Western Pacific Sub-tropical High and the upper tropospheric jet stream over East Asia are displaced southward, which prevents the East Asian summer monsoon from reaching as far north as in normal years. Furthermore, a cyclonic anomaly circulation at $850 \mathrm{hPa}$ occurs over SE China and an ascending (descending) anomaly motion south (north) of $\sim 30^{\circ} \mathrm{N}$ is seen over the study region, which contributes to the excess (lack) of rainfall south (north) of $\sim 30^{\circ} \mathrm{N}$ during SF/ND years. During the opposite phase of this mode, these circulation patterns are generally reversed.

Drumond et al. (2011, this Special) analyze the moisture sources over China and their variations during drier and wetter conditions of April-September in 2000-2004, using the Lagrangian FLEXPART model. They conclude that the contributions of moisture from the East and South China Seas to precipitation are significant for the eastern and southeastern coastal areas, while the Arabian Sea and the Bay of Bengal are more important sources of moisture for the southern and central regions of the country. The northern regions receive some moisture from western Asia in addition to the southern seas. They find that the regions dominated by moisture from non-local sources have higher spatial variability in moisture sources, whereas a lower variability of the distribution of the moisture sources appears in the regions dominated by local evaporation of moisture. 


\section{MODEL EVALUATION}

The capability of climate models to simulate variation of precipitation and extreme climate events at regional scales is still low, and this reduces the confidence in projections of the future climate. In East Asia, current climate models cannot reproduce the observed spatial and temporal variability of extreme precipitation events, due to the complicated landforms and the monsoon phenomenon. L. Zhang et al. (2011, this Special) use daily precipitation data of 1956-2009 to analyze the observed temporal and spatial variations of frequency of intense precipitation events (days with precipitation greater than the 95th percentile), and compare them with those simulated with the Beijing Climate Center Climate System Model (BCC_CSM1.0). The simulation is forced with observed greenhouse gas and aerosol concentrations in the atmosphere, solar irradiance and volcanic aerosols. The model approximately reproduces the temporal and spatial characteristics of the observed climatology of annual total precipitation and intense precipitation events. It captures some spatial patterns of the intense precipitation amount trends, especially in NE China. However, defects in the simulation include an underestimation of annual total precipitation and intense precipitation south of the Yangtze River, a general underestimation of the frequency of heavy precipitation days $(\geq 25 \mathrm{~mm}$ in $24 \mathrm{~h}$ ), and an overestimate of the frequency of light rain events $(0.1-10 \mathrm{~mm}$ in $24 \mathrm{~h})$. The model also calculates trends of intense precipitation amount and frequency that are the opposite of the observations in North and South China, and therefore requires improvement.

\section{DROUGHT RISK ASSESSMENT}

Zhao et al. (2011, this Special) evaluate the risk of agricultural droughts for winter wheat in northern Henan Province, China using precipitation data and the CERES-Wheat model. The methodology of the study is useful for analyzing temporal change in the risk of droughts or any other extreme events. The authors simulate the total potential yield and waterlimited potential yield, and use the yield difference to determine the effect of precipitation deficits on crop production, i.e. agricultural drought risk. A significant correlation exists between the modeled yield difference and the observed precipitation during the growth season for each of the 66 weather stations for 1962-2009. Minor droughts occurred more frequently in the southern area of the study region, moderate droughts were more frequent in the western and eastern areas, and the frequencies of severe droughts generally decreased from north to south. Although there are some limitations, the method has potential for further analysis of temporal variation in risk of agricultural droughts in the past, and the possible risk of agricultural droughts under varied GHGs scenarios in the future for rain-fed agricultural regions.

\section{CONCLUDING REMARKS}

This CR Special reports the progress in studies of change in climate extremes in mainland China from different perspectives. Complicated changes have occurred in the study region over the last $60 \mathrm{yr}$, especially relative to minimum temperatures, but many climate extremes remain unchanged. No significant linear trend is found for frequency of extreme climate events that have a major effect on socio-economic systems during the time period studied for the country as a whole. The historical perspective of the recent change of droughts and ice/snow storm event frequency over relatively small regions indicates that the frequency of extreme events in the last decades has not significantly surpassed average levels of the past centuries. These findings emphasize the difficulty of attributing observed changes in extreme climate events to anthropogenic impacts on the atmosphere. The relatively low capability of climate models (e.g. the BCC_CSM1.0) to capture the main features of change in extreme precipitation events at a regional scale also raises doubts over the projection of future anthropogenic extreme precipitation events.

An improvement in data processing and statistical methodology is needed in the analysis of changes in extremes occurring in China. In particular, inhomogeneities of land surface air temperature and precipitation data, and effects of micro-environmental change and urbanization near the climate stations need to be more thoroughly evaluated and adjusted for regional-scale analyses. More work should also be done to comprehensively assess regional extreme climate events and their changes, to evaluate and improve climate models, and to use climate models to study the mechanisms that drive the observed changes.

Acknowledgements. We thank all the authors for their contributions to this CR Special. We appreciate the helpful comments and suggestions on the individual manuscripts by the reviewers. This CR Special on mainland China is supported by the National Key Technology R\&D Program (2007BAC29B02). 


\section{LITERATURE CITED}

Alexander LN, Tapper N, Zhang XB, Hayley J and others (2009) Climatic extremes: progress and future directions. Int J Climatol 29:317-319

Choi G, Collins D, Ren GY, Trewin B and others (2009) Changes in means and extreme events of temperature and precipitation in the Asian-Pacific Network region, 1955-2007. Int J Climatol 29:1906-1925

Christidis N, Stott PA, Brown SJ (2011) The role of human activity in the recent warming of extremely warm daytime temperatures. J Clim 24:1922-1930

Ding Y, Ren G (eds) (2008) Introduction to Climate Change Science of China. China Meteorological Press, Beijing (in Chinese)

Drumond A, Nieto R, Gimeno L (2011) Sources of moisture for China and their variations during drier and wetter conditions in 2000-2004: a Lagrangian approach. Clim Res 50:215-225

Easterling DR, Horton B, Jones PD, Peterson TC and others (1997) Maximum and minimum temperature trends for the globe. Science 277:364-367

Guan Z, Han J, Li M (2011) Circulation patterns of regional mean daily precipitation extremes over the middle and lower reaches of the Yangtze River during the boreal summer. Clim Res 50:171-185

Hao Z, Ge Q, Zheng J (2010) Variations of extreme drought/ flood events over eastern China during the past 2000 years. Clim Environ Res 15:388-394 (in Chinese)

$>$ Hao Z, Zheng J, Ge Q, Wang WC (2011) Historical analogues of the 2008 extreme snow event over Central and Southern China. Clim Res 50:161-170

Huang L, Shao X, Liu H, Wang SZ and others (2010) A 2800 year tree ring record of severe sustained extreme drought events in the Qaidam Basin, Qinghai. Clim Environ Res 15:379-387 (in Chinese)

IPCC (2007) Climate change 2007: the physical science basis. Contribution of Working Group I to the Fourth Assessment Report of the Intergovernmental Panel on Climate Change. Cambridge University Press, Cambridge

Mao R, Gong DY, Yang J, Bao JD (2011) Linkage between the Arctic Oscillation and winter extreme precipitation over central-southern China. Clim Res 50:187-201

Peterson TC, Zhang XB, Brunet M, Vazquez-Aguirre JL (2008) Changes in North American extremes derived from daily weather data. J Geophys Res Atmos 113:123-138

Qian WH, Fu JL, Zhang WW, Lin X and others (2007)
Changes in mean climate and extreme climate in China during the last 40 years. Adv Earth Sci 22:673-684 (in Chinese)

Ren GY, Guo J, Xu MZ, Chu ZY and others (2005) Climate changes of mainland China over the past half century. Acta Meteorol Sin 63:942-956 (in Chinese)

Ren GY, Feng GL, Yan ZW (2010) Progresses in observed studies of climatic extremes and changes in mainland China. Clim Environ Res 15:337-353 (in Chinese)

Ren G, Chen Y, Zou XK, Zhou YQ and others (2011) Change in climatic extremes over mainland China based on an integrated extreme climate index. Clim Res 50:113-124

Stott PA, Gillett NP, Hegerl GC, Karoly D, Stone DA, Zhang X, Zwiers F (2010) Detection and attribution of climate change: a regional perspective. WIREs Clim Change 1: $192-211$

Trewin B, Vermont H (2010) Changes in the frequency of record temperatures in Australia, 1957-2009. Austral Meteorol Oceanogr J 60:113-119

Wang L, Huang Q, Dai A, Guan Z, He J, Wu Z (2011) Inhomogeneous distributions of Meiyu rainfall in the JiangHuai basin, and associated circulation patterns. Clim Res 50:203-214

Zeng Z, Fang X, Ye Y, Zhang X (2009) Disaster losses and causes of 3 extreme droughts in China over the past 300 years. J Catastrophol 24:116-122 (in Chinese)

Zhai PM, Pan XH (2003) Trends in temperature extremes during 1951-1999 in China. Geophys Res Lett 30:1913 doi:10.1029/2003GL018004

Zhai PM, Zhang XB, Wan H, Pan XH (2005) Trends in total precipitation and frequency of daily precipitation extremes over China. J Clim 18:1096-1108

> Zhang L, Dong M, Wu T (2011) Changes in precipitation extremes over Eastern China simulated by the Beijing Climate Center Climate System Model (BCC_CSM1.0). Clim Res 50:227-245

Zhang Y, Shao X, Yin ZY, Liang E, Tian Q, Xu Y (2011) Characteristics of extreme droughts inferred from treering data in the Qilian Mountains, 1700-2005. Clim Res 50:141-159

Zhao H, Gao G, Yan X, Zhang Q, Hou M, Zhu Y, Tian Z (2011) Risk assessment of agricultural drought using the CERES-Wheat model: a case study of Henan Plain, China. Clim Res 50:247-256

> Zhou Y, Ren G (2011) Change in extreme temperature event frequency over mainland China, 1961-2008. Clim Res 50:125-139 